\title{
Determination of Land and Marine Containment Sites of Oil Spills from Crude Oil Pipelines
}

\author{
Huseyin Murat Cekirge \\ Department of Mechanical Engineering, the Grove School of Engineering, the City College of the City University of New York, New York, \\ USA
}

\section{Email address: \\ hmcekirge@usa.net}

\section{To cite this article:}

Huseyin Murat Cekirge. Determination of Land and Marine Containment Sites of Oil Spills from Crude Oil Pipelines. International Journal of Environmental Monitoring and Analysis. Special Issue: Environmental Social Impact Assessment (ESIA) and Risk Assessment of Crude Oil and Gas Pipelines.Vol. 3, No. 6-1, 2015, pp. 26-38. doi: 10.11648/j.ijema.s.2015030601.14

\begin{abstract}
Containment sites are the most important locations for recovering spilled oil on land and marine environments. Analyses for determining of containment sites for crude oil pipelines are explained in detail. Necessary information for designing land and marine containment sites is introduced. The necessary databases for efficient response are also mentioned. The paper is guidance for planners who will design oil spill response plans.
\end{abstract}

Keywords: Land Containment Sites, Marine Containment Sites, Catchment Areas, Land Oil Spills, Oil Spill Response Plans, OSRP Databases

\section{Introduction}

A forecasting and trajectory model is necessary to follow and monitor the oil on land and sea. This program may help to resolve legal claims aftermath of the oil spill. Monitoring oil spills is;

- Spill size determination;

- Spill movements;

- Spill tracking that help Incident Command; and

- Environmental monitoring.

Oil spill can be initiated from oil tanks, terminal, open water, vessels and pipelines on land. OSRP (Oil Spill Response Plan) must consist of detailed information for each case, [1 - 6]. Based on the size and location of the whole installation, equipment depots should be established for proper response; even considering air transport for heavy equipment. The locations must be chosen for the most efficient response to onshore and offshore oil spills.

Land Spills: On land, oil spills start from pipelines and flow low spots by gravity and topographic contours through catchment areas and end up river beds, Figure 1. At the each kilometer point, an oil spill may start and reach a river bed, which is called "containment site". It is mostly required two containment site for every Kilometer Point, KP, in other words for a segment between two consecutive KP. The cleaning operations can performed at these containment sites. Each containment site must be analyzed; and the following information must be recorded in pictures, maps and sketches:

- Description of the site and directions;

- General cleanup options / equipment;

- Environmental sensitivity of the pipeline corridor;

- Pipeline crossings information; and

- Downstream environments.

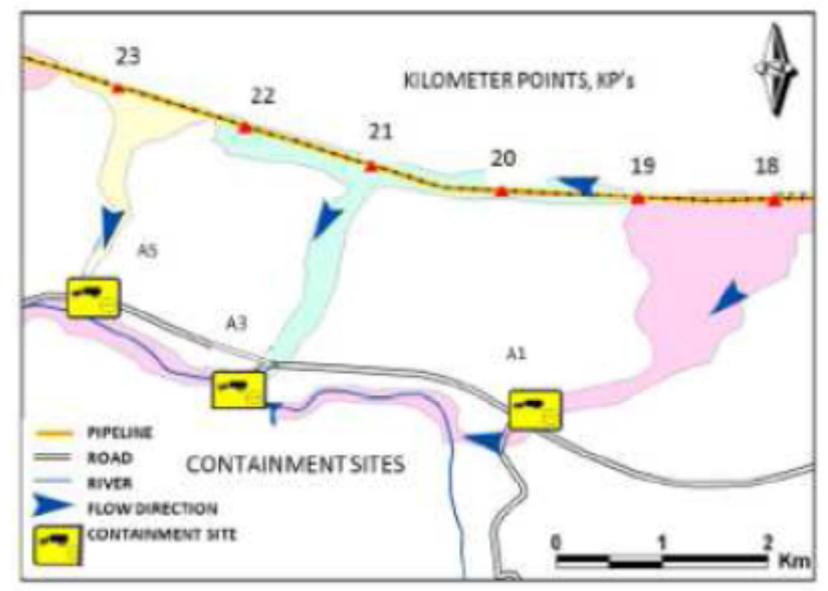

Figure 1. Down slope potential oil spill flow analysis (Catchment Area), related containment sites and pipeline KPs (Kilometer Points), [1].

The spills must be caught and cleaned from the equipment coming from equipment depots which are 
established best reachable location for containment sites, even considering Tier 1, Tier 2, and Tier 3, [1].

Oil will flow toward low spots under the influence of gravity. In general, it will follow gullies and dry creek beds at right angles to topographic contours toward surface water. At colder temperatures, crude oil in the pipeline system will become extremely viscous and may reach its pour point, below which it will be essentially immobile. The probable pathway of spill movement has been determined along the entire pipeline by analysis of topographic maps supported by fieldwork.

The degree of threat to groundwater presented by a petroleum hydrocarbon spill is subject to variables including the properties of the hydrocarbon, size and location of the release, permeability of the soil impacted, depth to groundwater, and effectiveness of any response action. Petroleum hydrocarbons will adsorb onto soil particles and be held in soil pore spaces by capillary action. Left uncontrolled, a fluid hydrocarbon spill will penetrate into a porous soil until it is absorbed and bound by soil particles or until it reaches an impermeable layer or groundwater. Soils typically can retain 15 to 40 liters of petroleum per cubic meter. If temperatures are below the pour point of the hydrocarbon, threat to groundwater is minimal.

Spills to Sediment Dominated Shorelines: Oil can become incorporated into beaches by burial (shifting sand) or penetration. Generally, the larger grain size results deeper potential penetration. At the extreme, it can be expected that penetration into coarse gravel/cobble beaches will be greater than on compacted sand or mud flats. On sand beaches, emulsions and waxy oils will not penetrate as readily as lighter oils and crudes. As a general rule, the maximum level of oil in sediment beaches is 10 percent by volume (where oil may be dripping out of the sediment). It should be mentioned that common levels are 2 to 5 .

Creeks and Streams: Oil entering creeks and streams will move downstream with the current. Maps prepared for the Containment Manual Database indicate estimated flow direction information and can be used to initially predict spill flow directions at any location along the pipeline. Some spreading may occur, particularly with diesel spills, but the spreading motion will typically be overcome by even a slight current. For planning purposes, assume that the oil will move at stream flow velocity without wind or other effects. In practice, oil will tend to accumulate in areas of quiet water, eddies, in vegetation, and in debris accumulations. Natural collection areas can frequently be identified by the presence of accumulated debris. Flow velocity can be estimated by timing the movement of a floating object, such as a stick, over a measured distance. Field measurement of ambient current conditions provides a useful method of identifying locations where booming can be successfully conducted.

Storm Drains / Culverts: Storm drains in the region may include buried pipes, open box culverts and lined or unlined channels. Oil entering storm drains may be lost from view and may be difficult and dangerous to recover. These features are confined spaces where dangerous concentrations of vapors may accumulate. As such, spills to storm drains can present significant fire and explosion hazard (especially for petrol spills) and constitute high-risk entry situations. Spills to storm drains may be assessed by carefully opening the nearest manhole cover and visually determining the direction of flow. If oil is present, checking observation down gradient continues until oil is disappeared. Vapor monitoring instrumentation may be used for tracing fluids and vapors. Oxygen deficient and explosive atmospheres may exist with all releases involving confined spaces. All releases to storm drains should be approached with caution.

Canals and Irrigation Channels: The pipeline may lie in proximity to many water supply canals and irrigation channels. Most of these canals have elevated banks and are exposed to spills only at points where the pipeline crosses them. Other water supply canals are located along major rivers, and generally have control structures which may be used to control floating oil. Flow velocities in canals can be estimated by timing the movement of floating debris over a known distance.

The purpose of this paper is to provide environmental and containment site information needed to respond efficiently during an oil spill incident generated by the operating company related activities. Information is provided on:

1. Ecological resources in the area and their seasonality;

2. The type of shorelines present and their general sensitivity to spilled oil;

3. Areas of human-use importance, particularly related to recreational use and fishing; and

4. Preplanned sites for the deployment of oil spill equipment, referred to as containment sites.

\section{Land Oil Spills}

For the pipeline, volume estimates can be calculated by adding the estimated volume lost by pumping and drainage of material free to gravity flow from the pipeline.

- Loss Due To Pumping: Loss due to pumping can be calculated by multiplying the pumping rate by the time elapsed from event discovery to pump shutdown. Specific data should be available from the pipeline control center.

- Loss Due To Drainage: After pumping has been terminated, sections of pipeline topographically above a point of failure will attempt to drain. Adjacent sections of the pipeline may be above or below the leak point and drainage may occur from one or both directions, depending on location. In addition, pipeline valves will influence pipeline drainage. Block valves have been placed at strategic locations to control the magnitude of potential spills by isolating pipeline segments and controlling the flow of oil in both directions.

Maximum pipeline loss may be complicated due to topography and the placement of block valve. To roughly determine the potential pipeline drainage, the contents of a pipeline from the topographic high down to the break point 
can be used. Block valves will reduce the potential flow if between the high point and the break point. Siphoning effects over topographic highs may occur, but are difficult to estimate.

The amount of oil contained in a contaminated land area may be estimated by using the following techniques:

- Classify the area: Land spills are usually irregular in shape. To begin with estimation of volume, classify the exposed area into either "flow" areas or "pooling" areas. Flow areas are those over which the oil moves, and typically contain an oil coating with minimal penetration. Pooling areas consist of depressions or low spots where oil accumulates. Soil penetration may occur in these areas.

- Estimate the area covered: To develop an estimate of the area covered by flow exposure or pooling, break each category into a series of rectangle or squares which approximate its shape. For edges, the rectangles should contain approximately fifty percent oiled surface and fifty percent unoiled surface. Multiply the length by the width of each rectangle and sum the totals to obtain the area estimate. The more rectangles you use, the more accurate your estimate will be.

- Estimate the Average Depth of the Oil: Oil will typically vary from very thin at the edges to thicknesses depending on the depth at the low points. Depths can be estimated by gauging with a stick at a number of locations. If the oil pool is wide or inaccessible, estimate probable depth by projecting the general surface profile to the center of the pool.

- Calculate the Free Oil Volume: Multiply the estimated areas by the estimated average depths to obtain free oil spill volume. Roughly 1 cubic meter of oil is 1 ton and equal to 7 barrels.

- Estimate Penetration into Soil: Oil may penetrate into soils. The depth of penetration is determined by factors including soil type and porosity, viscosity of the oil, temperature, and presence of water. Field observations should include sufficient small excavations to determine whether soil penetration has occurred and if it has, how deep. If penetration has occurred, estimate the depth by excavation. It should be checked to determine whether oil in the soil is mobile by allowing a contaminated sample to drain. Any oil which will drain is free to migrate vertically or horizontally through the soil. Penetration estimates are necessary for assessing the impact and identifying appropriate response actions.

- Burrows: In some areas spilled oil may enter animal burrows. Depending on its characteristics, oil entering burrows may remain in the burrow, or soak into surrounding soils. Oil hidden in burrows is often a source of long term recontamination.

- Estimate Penetration into Snow: In cold temperatures below its pour point, the pipeline system crude oil into snow is anticipated. However, other hydrocarbons may exhibit the ability to soak into snow. When evaluating potential contamination in snow, always consider the fact that spillage may be hidden from view by recent snowfall. Small observation trenches may be necessary to determine presence and extent of contamination in such cases. Always plot the location of any contamination on snow so it can be re-located after additional snowfall. It is recommended that this be done by walking the perimeter of the spill area using a handheld GPS unit and downloading the resulting track line. It is also advisable to stake locations around the perimeter of the spill. This oil must be recovered right before snow in the start to melt.

- Tank-related spills: These include spills from above ground storage tanks and tanker trucks. The volume of tank spills may be estimated by comparing pre-spill fluid levels with post-spill levels or with the height of the hole, assuming the tank dimensions or capacity is known.

\subsection{Containment Sites}

The containment sites are the most important for mitigation of oil spills and its effects on environment. These sites must be determined as the end of the catchment areas, every one kilometer segment should be assigned at least two containment sites for the collection of spilled oil. The equipment depot must be at distance in which the response must be started according to the operating company's policy.

These containment sites must be regularly inspected and the pertinent data must be collected. The "Containment Site Database" must be designed and updated. There other response databases are:

Equipment database: The database for locating available equipment could be used during oil spills. This database is designed for obtaining equipment from the local and international resources.

Notification Database: The database for notifying authorities and interested parties who can help response activities. These parties could be governmental, private, medical and legal organizations that will facilitate the response activities and accommodation of the response staff. It is again, the databases must be updated regularly and tested for its functionality.

Mammal database: The database contains in mammals around the pipeline.

There may be some other databases related to transported crude oil and environmental conditions of the pipeline location.

The data collected for the containment site are as follow:

- Location;

- Pipeline information;

- Necessary and proper for equipment for the site;

- Sensitivity of the area and

- Pertinent topographical environmental maps; and

- Pictures.

These data can be seen in Figures 2, 3, 4 and 5.

Equipment list for the equipment depots can be prepared after the analysis and determination of appropriate equipment for the the containment sites. 


\subsection{Tracking Oil in Groundwater and Karst Areas}

In areas where groundwater has been contaminated, wells adjacent to the contamination site will be monitored for oil contamination. Professional scientists will set up the monitoring and instrumentation program working with the government water agency, and related organizations.

In karst areas, and in areas with few or no operating water wells, new wells must be drilled and pumped to determine the extent of subsurface contamination. This is a highly specialized field. Personnel from local groundwater organizations will be consulted to oversee and/or advise on such operations.

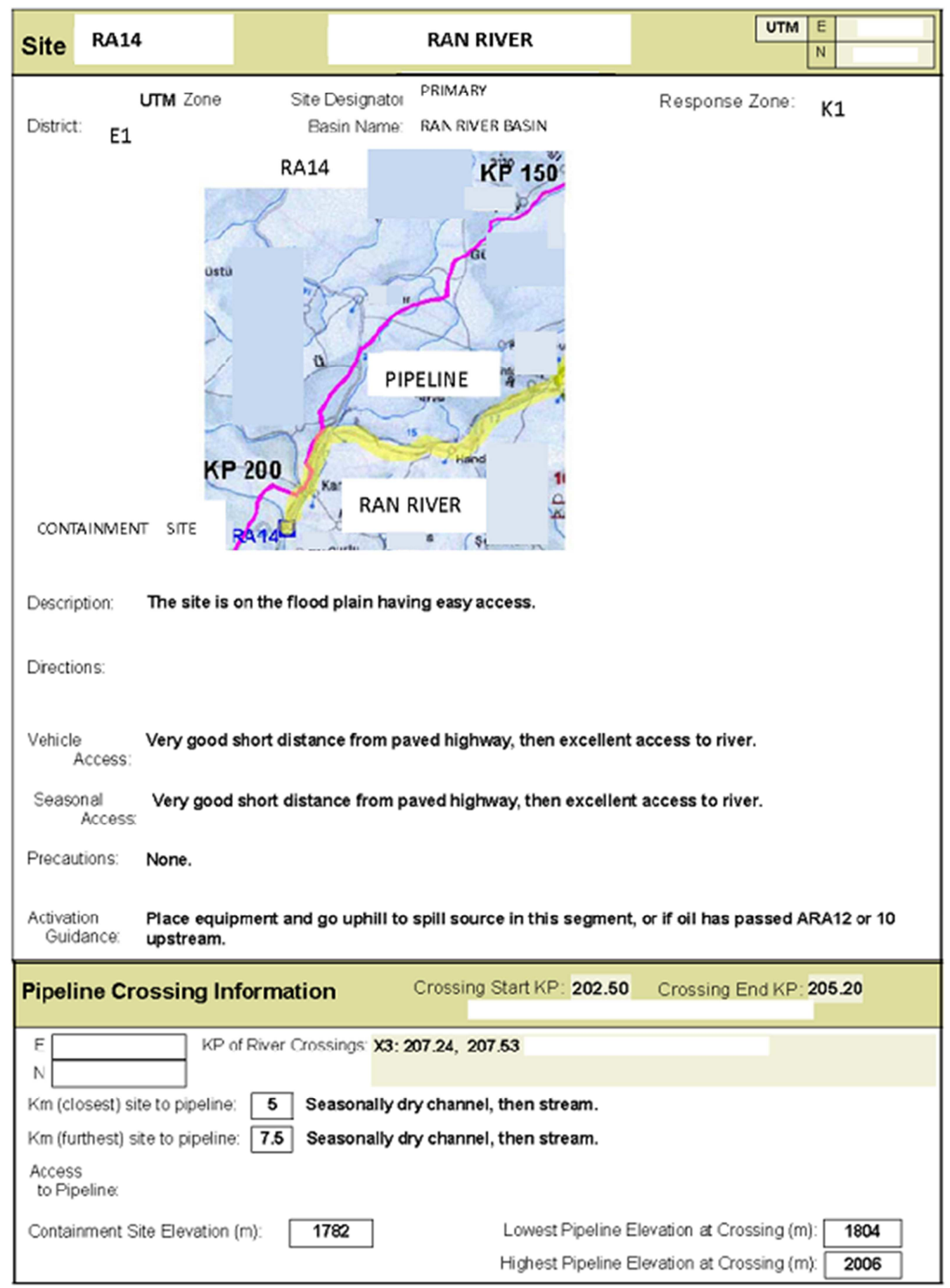

Figure 2. The location of the containment site, [7]. 


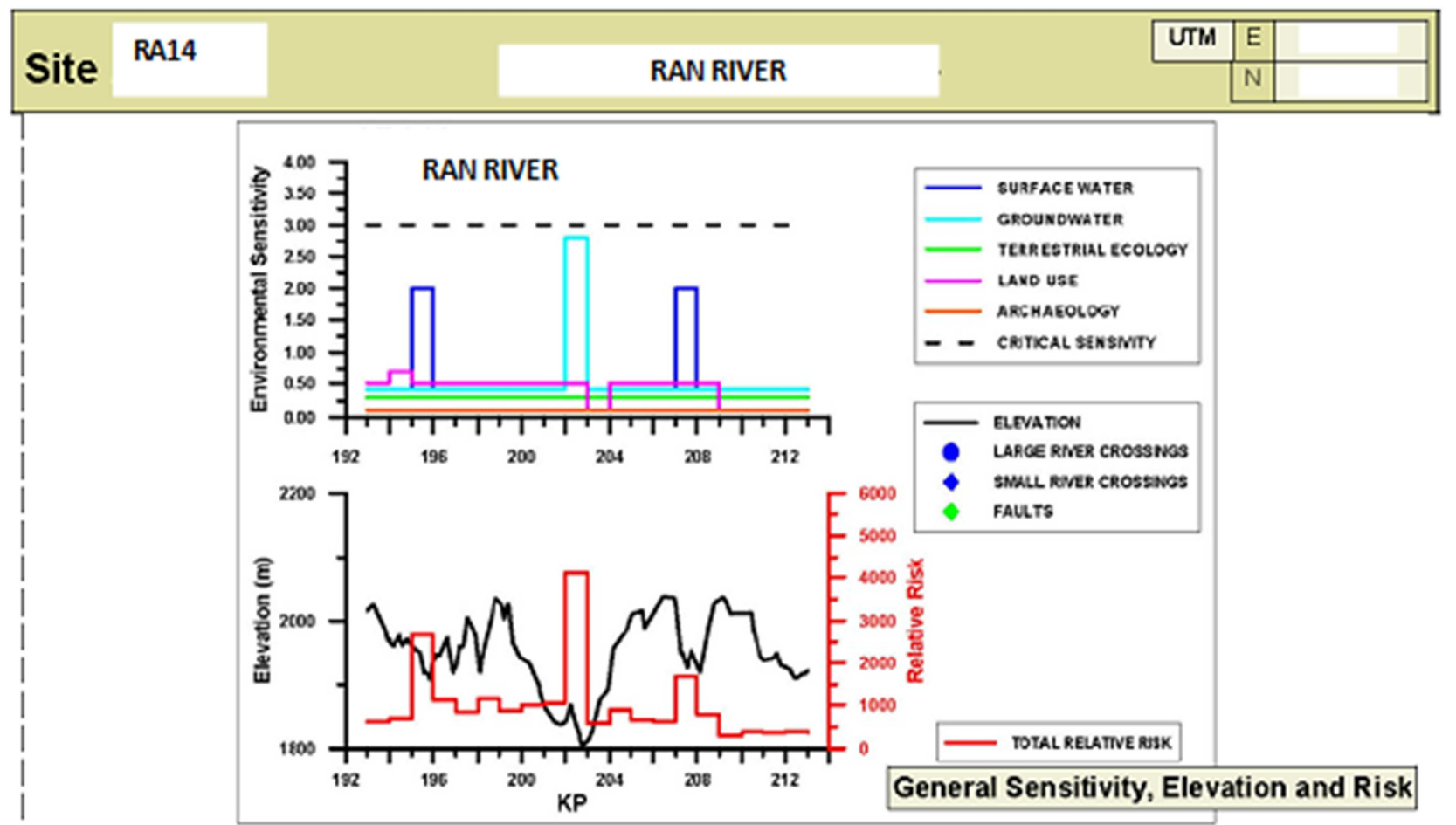

River Conditions and General Cleanup Options / Equipment See OSRP for other altematives.

\begin{tabular}{|c|c|c|c|c|}
\hline \multicolumn{2}{|c|}{ Boom+skimmer, Filter fence, Weir system, } & ystem, & \multicolumn{2}{|c|}{ Boom+skimmer. } \\
\hline Inshore / Fastvrater Boom (m): & 20 & Normal Flow (Survey) & 80 & Maximum Flow \\
\hline Inflatable Boom (m): & 0 & & $\mathbf{0}$ & \\
\hline Shoreseal Boom $(\mathrm{m})$ : & 10 & & 10 & \\
\hline Permanent Boom $(\mathrm{m})$ : & 0 & & 0 & \\
\hline
\end{tabular}

Boom Comments: None.

Skimmer Comments: None.

Other Equipment: No special equipment required.

Laydown Area (m2): $\quad 8,000$

River Width (m)

\begin{tabular}{|c|}
\hline 10 \\
\hline 0.35 \\
\hline 0.5 \\
\hline
\end{tabular}

River Conditions (Survey)

\begin{tabular}{|c|}
\hline 20 \\
\hline 2 \\
\hline 1.0 \\
\hline
\end{tabular}

Max. River Flow

River Depth (m)

River Velocity $(\mathrm{m} / \mathrm{s})$

Bank Condition: No bank, level.

\section{Contaminated Material Storage}

Storage Type: Fastanks, Pits.

Estimated Volume Needed (m3):

Figure 3. The sensitivity and proper equipment of the containment site, [7]. 


\begin{tabular}{|lll|l|l|l|}
\hline \multirow{2}{*}{ Site } & RA14 & UTM & $\mathrm{E}$ & \\
\cline { 3 - 6 } & RAN RIVER & $\mathrm{N}$ & \\
\hline
\end{tabular}

\section{Response Depots and Adjacent Containment Sites}

\begin{tabular}{|c|c|c|c|c|c|}
\hline Primary & K1 & Distance $(\mathrm{km})$ : & 161 & Time (hrs): & 2.3 \\
\hline Secondary & F1 & Distance $(\mathrm{km})$ : & 318 & Time (hrs): & 4.5 \\
\hline
\end{tabular}

Downstream

Upstream:

Site Gravelly stream with stream bank vegetation in wide food plain with adjacent agricultural land.

Environment:

Archaeology None evident, high caution level during site work because identified major archaeologic al site is and Cultural: loc ated within $5 \mathrm{~km}$.

Land Use: Agricultural / grazing.

Industry: None.

Ownership Unknown.

Percent Cover: Trees: 0 Shrubs: 5 Grass: $30 \quad$ Livestock? No Good Drainage? Yes

Site Sediments: Gravel.

Wildlife Observed: Birds

\begin{tabular}{|c|c|c|c|c|c|}
\hline \multicolumn{2}{|c|}{ Pipeline Environmental Sensivity Index } & Highest ESI Present: & At KP: & to $\mathrm{KP}:$ & \multirow{2}{*}{$\begin{array}{l}205.20 \\
205.20\end{array}$} \\
\hline Description: & Primarily Farm or Grazing Land. & KP of Segment from: & 202.50 & KP Segment End: & \\
\hline \multicolumn{6}{|c|}{ None. } \\
\hline
\end{tabular}

\section{Downstream Receptors and Major Sensitive Features}

Primary Downstream Receptor: Aras River / stream flora and fauna, + villages / towms.

\begin{tabular}{|c|c|c|c|c|c|}
\hline Sensitive Feature: & & & & Non & \\
\hline $\mathrm{Km}$ from the Pipeline: & $\mathbf{0}$ & KP Segment Start: & 202.50 & KP Segment End: & 205.20 \\
\hline Information & & KP Feature Start: & 202.50 & KP Feature End: & 205.20 \\
\hline
\end{tabular}

Description: 


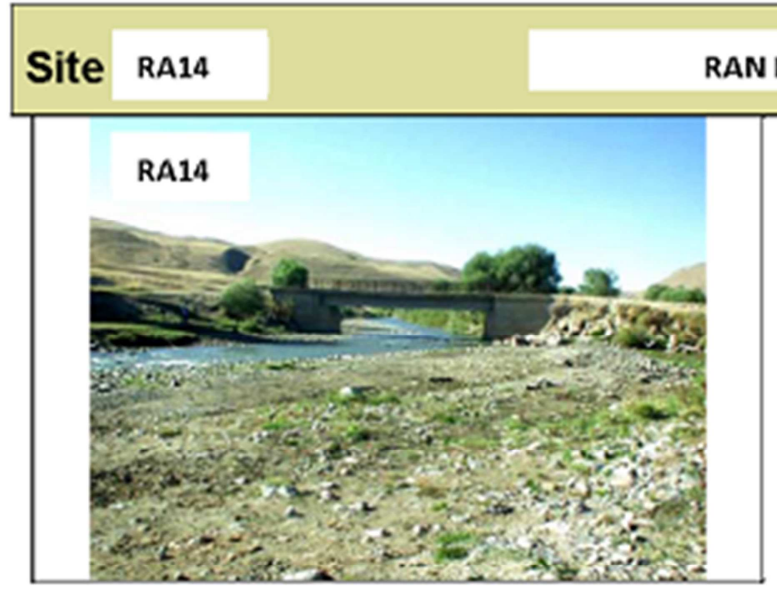

The bridge

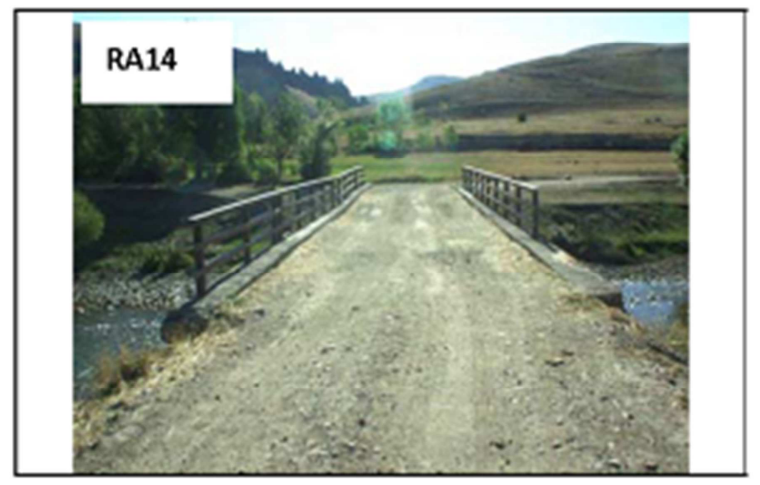

The bricge

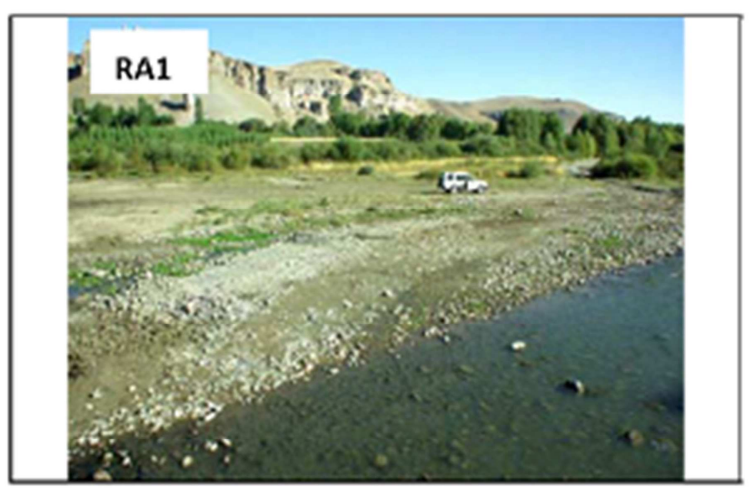

Overviaw of the area.

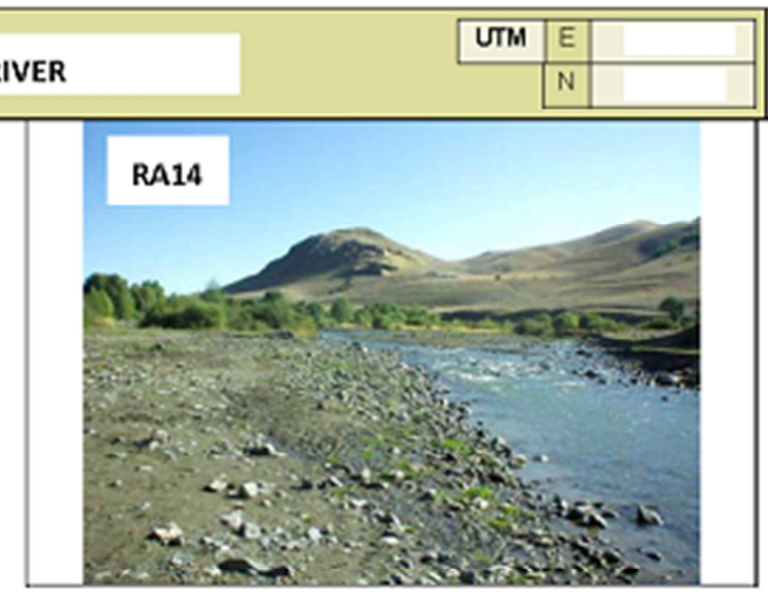

River.

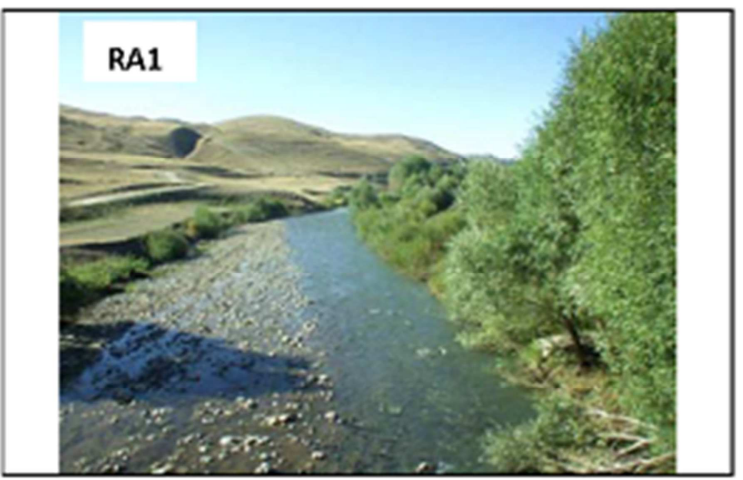

River from the bridge

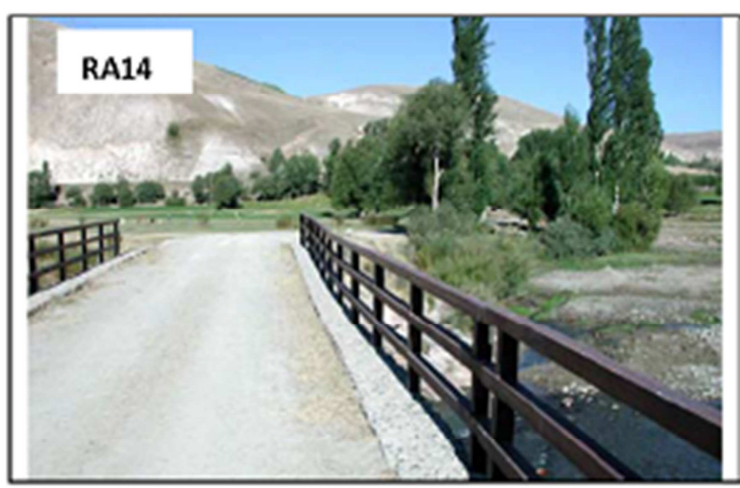

The bridge.

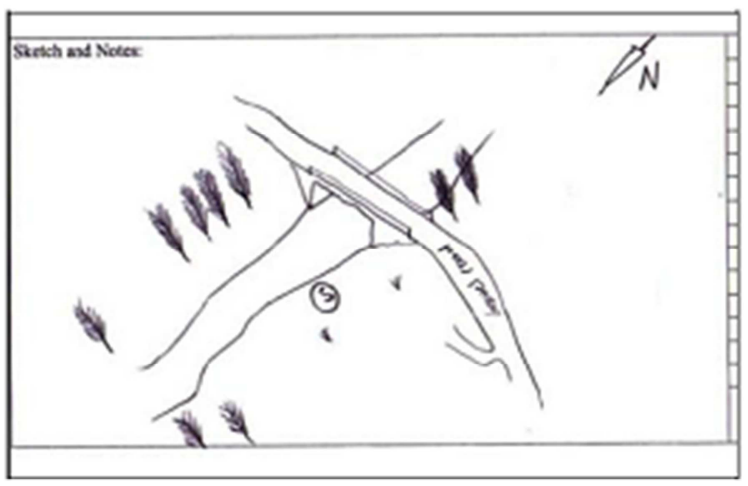

Skerch of site.

Figure 5. Pictures of the containment site, [7]. 


\subsection{Monitoring Guidelines}

The basis of an environmental monitoring program is to detect change in selected parameters over time. It will be carried out in two parts:

- Comparisons of post-spill data with pre-spill data (a baseline);

- Comparisons of post-spill data from the polluted area with data from an unpolluted, representative reference or control area; and

The baseline identifies conditions before the incident. The reference or control area provides information on natural site-to-site and seasonal fluctuations.

The design of a monitoring program will focus on objectives and specific measures to be used, i.e. 'endpoints'. For most credible scientific studies, a testable hypothesis will be formulated. For example,

- Objective: Does manual clean-up affect the recovery rate of oiled areas?;

- Hypothesis: Manual clean-up of areas does not influence the long term recovery compared to no treatment; and

- Endpoint (Measure): Distribution and percentage cover of flora by oil within manually cleaned, uncleaned and unpolluted areas.

The basis of monitoring is to identify changes through time. However, if change is identified, the cause of change is not always directly attributable to the oil spill that prompted the study.

There can be large natural fluctuations in community structures and species populations. The use of reference areas would serve to identify these and prevent them being attributed to an environmental stress such as an oil spill. When formulating monitoring objectives, any relevant constraints should be recognized and their impacts taken into account.

The specifics of a monitoring program are dependent upon the details of any given incident. Among factors to consider are:

- Identification of relevant baseline information;

- Inclusion of proper and useful reference or control sites in the study;

- Establishment of objectives of the monitoring program, including endpoints;

- Establishment of sampling methodologies; for example quantitative versus qualitative measurements;

- What constraints are being applied and what mitigations can be brought to carried on; and

- External reviews, such as peer review of the study and results and engagement of the general public.

\section{Marine Oil Spills}

As appropriate, the operating company will establish a spill tracking and monitoring program to assist in assessing the conditions of the affected marine and the continuing effectiveness of the response activities. This program may also assist resolving damage claims. Close liaison will be maintained with communities affected by the spill to ensure their concerns are addressed. The program may be relatively simple for small spills show little impact, or very complex for large spills or spills affecting particularly complex or sensitive habitats.

The implementation of a well-planned monitoring program facilitates a greater understanding of the specific impacts of an incident, as well as improving overall knowledge for future incidents. Key elements of the spill tracking and monitoring program include:

- Spill Size Assessment - Estimating spill volumes;

- Spill Movement - Estimating where oil will go;

- Spill Tracking - Monitoring of the characteristics and movement of released oil will be conducted periodically during the event to provide real-time information to Incident Command. Shoreline Cleanup Assessment Teams (SCAT) may be required to document the extent and distribution of shoreline oiling; and

- Environmental Monitoring - Involving regular monitoring after an incident up to the point where agreement is reached that remediation is complete, thereby providing information on the progress of recovery in the area.

The operating company will provide oversight and work with the Response Contractor to provide documentation, observations and sampling of the ephemeral and longer term environmental impacts of the oil spill and associated cleanup operations, striving in all cases to reduce the short and long impacts of these operations.

\subsection{Spill Size Assessment}

Terminal: A preliminary estimate of the size of a pipeline spill is necessary to gage the size of the response. It can be made from the SCADA system, from calculating pumping loss from the time of the incident until shutdown, from estimates of static pipeline drainage, and from visual estimates. It is important to treat calculations based on visual observations as preliminary, and for response planning purposes only. The magnitude of the release may change with time. In any case, precise calculation of the volume of a release is difficult and may not be possible until the pipeline is repaired. Release figures may be used to set fines and assess damages.

Vessel Related: Losses from tanker vessels will primarily be related to spills from the cargo or fuel tanks. Before and after measurements are most commonly used to determine the actual losses. If a rupture occurs during a loading operation, then spill size can be calculated based on hole size and location of the leak, and estimated leak duration. The location of the hole with respect to the waterline and interior fill line is important. The pressure head inside the cargo tank must be greater than the outside pressure for material to exit. The amount exiting a tank will eventually reach equilibrium with the outside water pressure if the leak is below the water line. These calculations can be difficult and sufficient information is typically not available during the first stages of a spill. 
Open Water: Once oil is on the water, accurate visual estimates are difficult to achieve because spilled oil is seldom uniformly distributed. The basic procedure involves estimation or measurement of the spill surface area, multiplied by its estimated average thickness of the oil. The thickness of oil on water can be estimated from its color, [8 - 10].

Emulsions: In some cases, mechanical energy may have mixed water into spilled crude oil, forming an emulsion, or mousse. A practical measure of emulsion stability and percentage can be obtained by allowing an oil sample to sit in a glass container and after 12 to 24 hours, measure the water fraction (water layer, if any). Refined products are not expected to demonstrate significant emulsification.

\subsection{Estimating Spill Movement}

Open Water - Using a Computer Model: An oil spill fate and trajectory model must be available for use at marine terminal. Utilizing actual winds and concurrently measured tides, the model provides an estimate of spill movement under the actual conditions present at the time of the spill. The procedures for model use must be developed.

Open Water - Vector Addition: Spilled oil movement on water can be estimated graphically by adding wind and current vectors. Surface currents will dominate spill movements unless the winds are extremely strong. Observations in actual spill situations have shown that wind will cause an oil slick to move at about $3 \%$ of the wind speed, and in the same general direction.

\subsection{Tracking and Surveillance}

The design of a monitoring program will focus on objectives and specific measures to be used, i.e. 'endpoints'. For most credible scientific studies, a testable hypothesis will be formulated to investigate affects of clean-up on the recovery rate.

A key element in an effective spill response is knowledge of where the spilled oil is located and tracking its movements. The environment unit will work to provide the appropriate level of oil spill tracking required by Incident Command. This section describes procedures for effectively tracking oil when:

- On the water's surface (rivers, lakes and oceans);

- On shorelines;

- Below the water's surface (i.e. sunken oil) and

- Underground movement via groundwater or in karst areas.

In all cases, the location of the observation is important. To this end, 1:30,000 detailed topographic maps with UTM (Universal Transverse Mercator) coordinates must be prepared for the entire route and areas of potential marine impacts. The specific location of the observation must be determined using a GPS (Geographic Positioning System). Photographs and video imaging can be marked and/or coordinated to GPS location by using software and titling units. Suppliers able to provide this expertise during oil spills are listed in the Contacts Database.

Aerial surveillance via helicopter is the fastest and best method to track oil on the water's surface where long distances are involved, and also offshore. Fixed-wing or twin-engine aircraft may be a required alternative. The Contacts Database provides information to obtain a helicopter or fixed-wing from government and private sources.

General rules for aerial surveillance are as follows:

- Trained or experienced observers should be utilized;

- Communication to the pilot must be maintained via headsets and hand signals;

- The observer should sit in front with the pilot;

- The ability to view through an open window is preferred; and

- Low altitude $(200 \mathrm{~m})$, slow flight is preferred, with the necessity of going up or down, or landing, for oil verification.

During the initial spill stages, frequent overflights (two or more times a day) are necessary:

- Detailed $(1: 30,000)$ maps must be brought on board to mark the flight path and mark the distribution of oil;

- Oil is likely to be patchy (for example, large areas of no oiling followed again by oiled shorelines or offshore patches are common) and

- The NOAA (National Oceanic and Atmospheric Administration) Open Water Oil Identification Job Aid (http://response.restoration.noaa.gov/shor_aid/shor_aid. html), [11], may be used, providing:

- Checklists;

- Photo examples of oil (and oil-similar material) on the water's surface;

- Example overflight maps; and

- Glossaries and charts.

Tracking Oil on Shoreline: Shoreline surveillance is carried out by a combination of aerial and ground surveys with the purpose of determining oil concentrations on the shoreline to advise Operations for cleanup. This is a highly specialized activity, and these activities must be done correctly. The Contacts Database lists companies available to provide this service, [12-16].

Tracking Oil below the Water's Surface: Highly weathered or bunker oils, or oils combined with sediment, may sink below the surface of the water, presenting a much more difficult problem in tracking the distribution of the spill. Methods to determine oil in the water column or on the bottom include:

- Small fishing nets, partially lined with sorbents, to verify oil presence (black spots on the white sorbent);

- Sorbent pads attached to a weight or anchor, and dropped to the bottom;

- Bottom dredges (used to collect shellfish); and

- Oceanographic benthic (bottom) survey instruments (grab sampler).

A portable flow-through fluorimeter may also used to track dissolved oil in the water column, but involves sophisticated instrumentation. 


\subsection{Onshore Containment Sites}

Spilled oil finally moves towards to shorelines and threatens environmentally sensitive areas; and these areas are estuaries, lagoons and beaches. The oil spilled from pipelines and pipeline's operations threatens marine areas of the pipeline terminal. The sensitive areas and containment sites can be determined by simulating oil spills for various environmental and meteorological conditions. Once, these sensitive areas areas determined, these are considered like land containment sites for collecting spilled oil in marine environment. These areas must be inspected, and the pertinent data of the area are collected for establishing a database. The

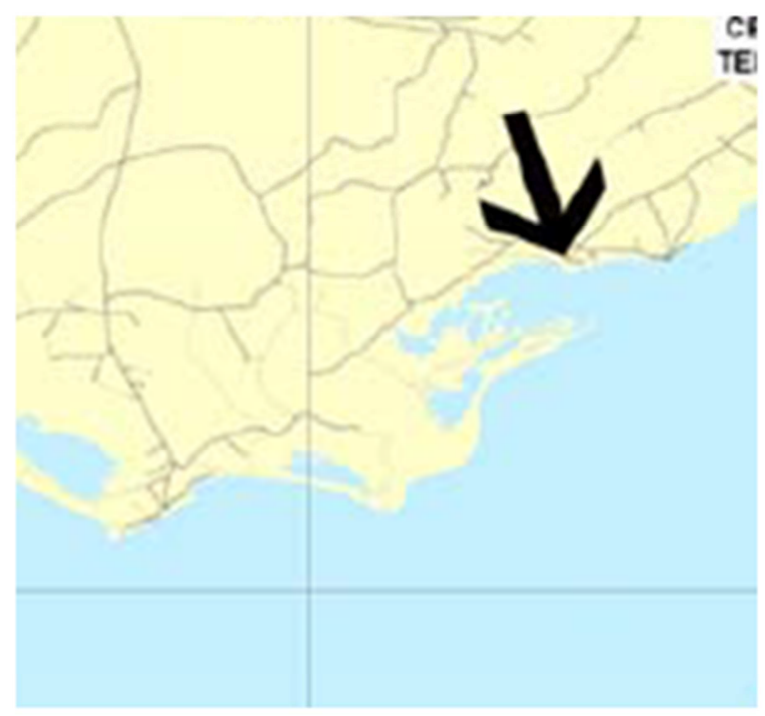

The containment site, lagoon.

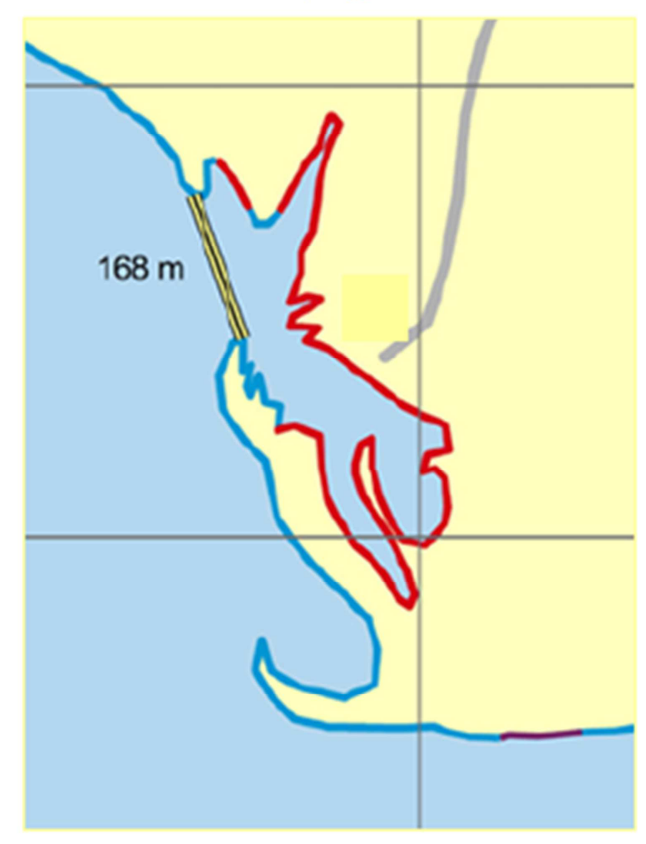

Sketch of the containment site. rules of marine containment sites are same as the land containments sites. The difference is the activation process, which is determination of the containment sites that will be threatened by the actual oil spills in the area. After activations process, all the actions for recovering oil in containment sites will be started.

The equipment for each containment site must be selected; and then the equipment inventory for marine spills of response depots can be determined. These equipments will be in the general equipment database which will be used together with notification and other databases. The details of the pertinent data are presented by Figures 6, 7 and 8 .

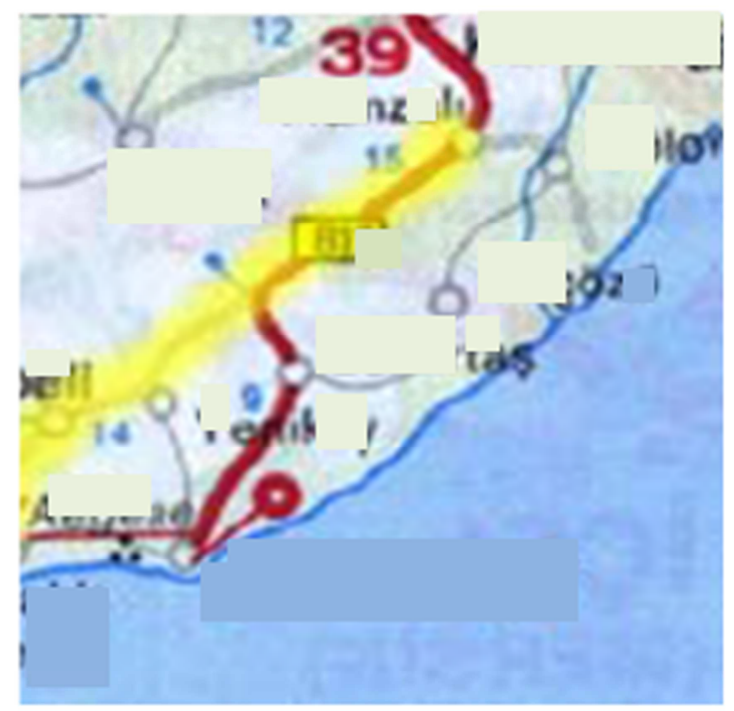

Road Map

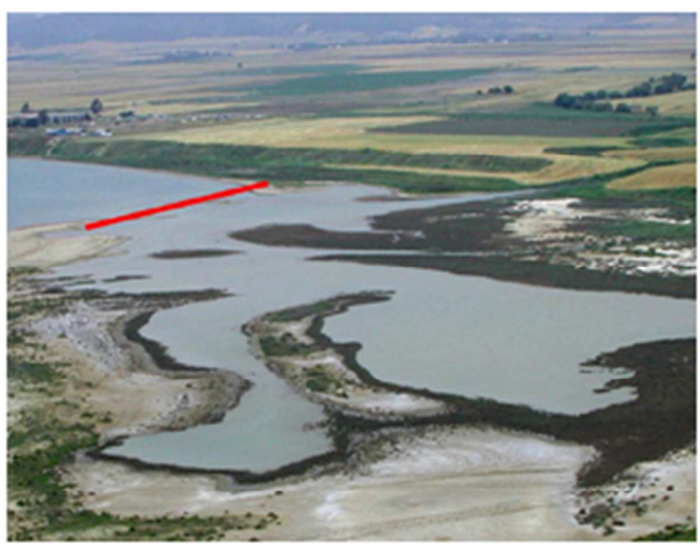

Protection of the containment site.

Figure 6. Onshore containment site, [17]. 


\begin{tabular}{|l|c|c|c|c|}
\hline \multicolumn{7}{|c|}{ Guideline for Site Activation* } \\
\hline Spill Location & $\begin{array}{c}\text { Small } \\
(<500 t)\end{array}$ & $\begin{array}{c}\text { Medium } \\
(500-10,000 t)\end{array}$ & $\begin{array}{c}\text { Large } \\
(1,000-30,000 t)\end{array}$ & $\begin{array}{c}\text { Very Large } \\
(>30,000 t)\end{array}$ \\
\hline TERMINAL & Monitor & Monitor & Activate & Activate \\
\hline
\end{tabular}

"This activation guide is based on results of oil spill modeling. As actual conditions may vary from those used in the model, actual spill movement should always be monitored visually and response activation requirements adjusted as necessary.

Response Options and Strategy

The strategy is to deploy boom, filter fence or shoreseal boom across the entry channel to protect a small sensitive marsh area from incoming oil.

Because of the shallow nature of the opening to the embayment, shoreseal boom or filter fencing are likely to be appropriate.

Nearshore boom should be brought to site to provide an alternative should conditions at the time warrant deployment.

Sand bags can also be placed across the inlet opening (allowing some circulation) or can be used as anchoring.

\section{Site Characteristics}

The total entry channel is approximately $170 \mathrm{~m}$ wide, bounded by a sand spits on both sides. Currents are weak and waves are very low. Because of infilling, the actual opening of the site is likely to be less than $50 \mathrm{~m}$.

Directions and Staging

Continue south-southwest on the paved road; and the paved road ends at intersection to the town. Continue south on dirt road to the shoreline. The staging area is on the shoreline at the end of the road. The site is one hour from the town.

Sensitivity

The site is a marsh / tidal flat area that supports a variety of plant species and a large number of birds.

\section{Equipment}

Shoreseal boom: $60 \mathrm{~m}$.

Inshore boom: $100 \mathrm{~m}$.

Sorbent boom: $100 \mathrm{~m}$.

Anchors: 4.

Stakes for boom: 4 .

Sand bags: 100 .

$1,000 \mathrm{~m}^{2} 5 \mathrm{~mm}$ plastic sheeting.

10 bags sorbent pads.

10 boxes heavy duty garbage bags.

1 skip (to be lined) for waste products.

Vacuum truck and flatbed truck to transport wastes.

\section{Response Actions}

From the staging area, deploy and monitor boom .

Angle boom sufficiently to prevent oil entrainment (oil passing under the boom).

If considered to be effective, string 1 length sorbent boom behind each hard boom.

Store small quantities of oil in temporary storage tanks.

Remove oil from the shoreline.

Segregate and store wastes.

After incident, remove vestiges of spill and equipment.

Restore the area.

Figure 7. Activation conditions and appropriate equipment for the containment site, [17]. 

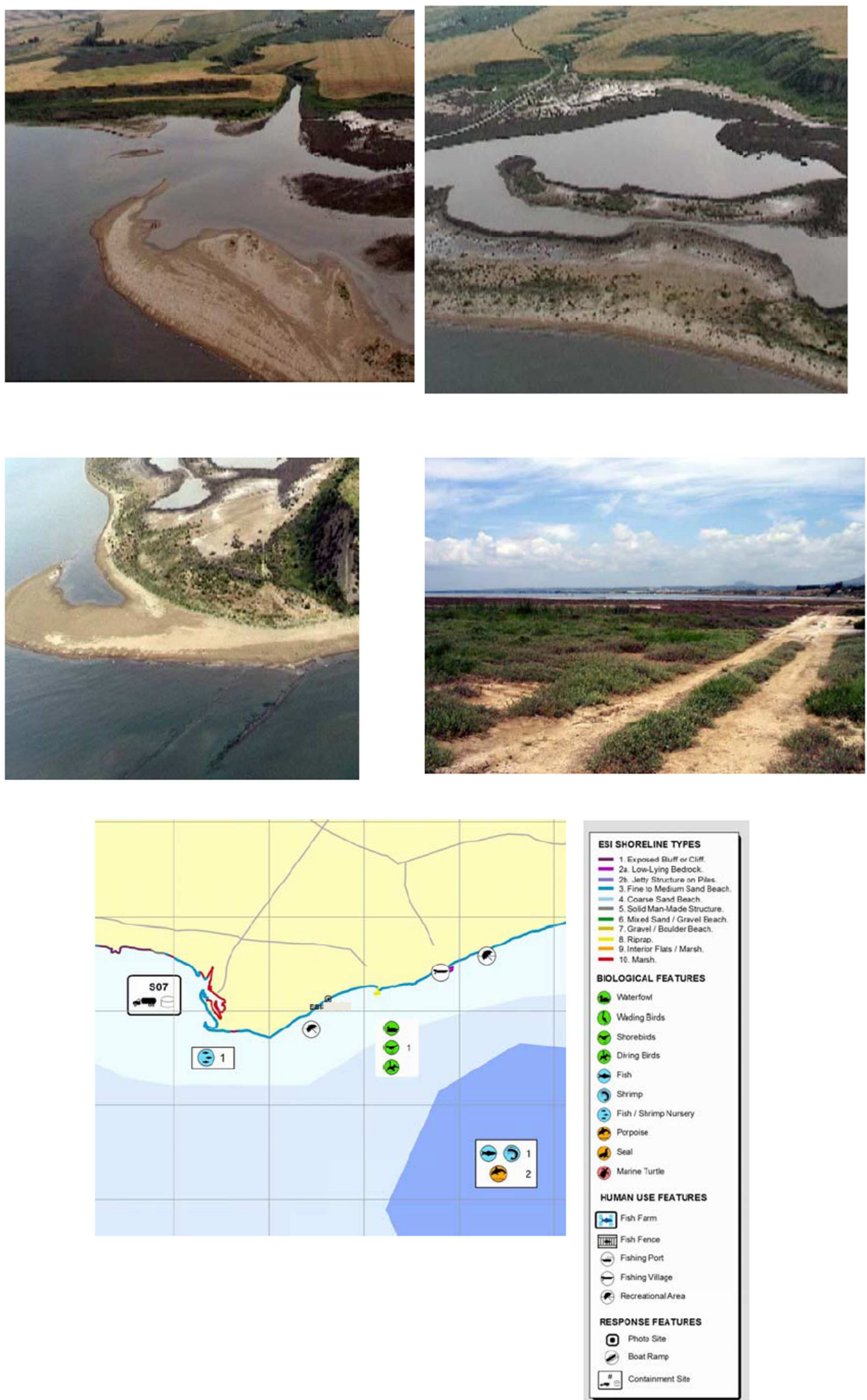

Figure 8. Pictures and sensivity of the containment site, [17]. 


\section{Conclusions}

The paper presents detailed analysis of determination of land and marine containment sites for crude oil pipelines. The data must be collected to design these containment sites, and the related databases must be prepared and regularly updated. The procedure of determination of these sites and the required data are explained, and practical examples are given including pictures. The methodology is the directions for preparing oil spill response plans.

\section{References}

[1] Huseyin Murat Cekirge. Outlines of an Oil Spill Response Plan (OSRP) for Crude Oil Pipelines. International Journal of Environmental Monitoring and Analysis. Vol. 3, No. 3, 2015, pp. 191-197. doi: 10.11648/j.ijema.20150303.21.

[2] Z. Zhong $\mathrm{Z}$ and Y. You, Oil spill response planning with consideration of physicochemical evolution of the oil slick: A multiobjective optimization approach, ANL/MCS-P1786-0810, Mathematics and Computer Science Division, Argonne National Laboratory, 2010.

[3] D. Mackay, I. A. Buis, R. Mascarenhas R and S. Paterson, Oil spill processes and models: Environment Canada, Manuscript Report No 8. EE-8; Ottawa, Ontario, 1980.

[4] N. P. Ventikos, E. Vergetis, H. N. Psaraftis and G.Triantafyllou, A high-level synthesis of oil spill response equipment and countermeasures. Journal of Hazardous Materials; 107:51-58, 2004.

[5] R. G. Pond, D. V. Aurand and J. A. Kraly, Ecological risk assessment principles applied to oil spill response planning in the Galveston Bay Area, Texas General Land Office, Austin, Texas, 2000.

[6] Z. Zhong and F. You, Oil spill response planning with consideration of physicochemical evolution of the oil slick: A multiobjective optimization approach, Computers \& Chemical Engineering, 08/2011; 35(8):1614-1630. DOI: 10.1016/j.compchemeng.2011.01.009, 2011.
[7] H. M. Cekirge, Pipelines, Maltepe Uni., Int. Rep. 1/2, Istanbul, 2010 .

[8] H. M. Cekirge, Oil spills and shorelines, Maltepe Uni., Int. Rep. Cekirge, H. M., "Oil Spills: Determination of Oil Spill Volumes Observed on Water Surfaces", The International Journal of Technology, Knowledge And Society, 8 (6), 17 - 30, 2013.

[9] W. J. Lehr, R. J. Fraga, M. S. Belen, and H. M. Cekirge, "A New Technique to Estimate Initial Spill Size Using a Modified Fay-Type Spreading Formula," Marine Pollution Bulletin, 1 5(9), 326-329, 1984.

[10] W. J. Lehr, H. M. Cekirge, R. J. Fraga and M. S. Belen, "Empirical Studies of the Spreading of Oil Spills", Oil and Petrochemical Pollution, 2 (1),7-11, 1984.

[11] NOAA (National Oceanic and Atmospheric Administration) Open Water Oil Identification Job Aid (http://response.restoration.noaa.gov/shor_aid/shor_aid.html), 2010.

[12] NOAA (USA, National Oceanic and Atmospheric Administration) Shoreline Assessment Job Aid: (http://response.restoration.noaa.gov/shor_aid/shor_aid.html), 2010 .

[13] Environment Canada, (http://www.etc-cte.ec.gc.ca/estd_west/estdwest_scat_e.html\# 02), 2010

[14] NOAA (National Oceanic and Atmospheric Administration), ( http://response.restoration.noaa.gov/oilaids/shore/shore.html), 2012.

[15] Environment Canada, (http://www.etc-cte.ec.gc.ca/estd_west/SOS\%20FORM.pdf.), 2010 .

[16] NOAA (National Oceanic and Atmospheric Administration), Assessment of the Risks Associated with the Shipment and Transfer of Group V Fuel Oils (NOAA, 1994), (http://response.restoration.noaa.gov/oilaids/GroupV.pdf), 1994.

[17] H. M. Cekirge, Oil spills and shorelines, Maltepe Uni., Int. Rep. $1 / 3$, Istanbul, 2010. 